\title{
ALEXANDRIA
}

Revista de Educação em Ciência e Tecnologia

ALEXANDRIA

\section{Encontros com a Matemática na Terra de $\mathrm{Oz}$}

\section{Mathematical Encounters in the Land of $\mathrm{Oz}$}

\section{Letícia de Queiroz Maffei ${ }^{a}$; João Alberto da Silva ${ }^{b}$}

a Centro de Educação Ambiental, Ciências e Matemática, Universidade Federal do Rio Grande, Rio Grande, Brasil letimaffei@gmail.com

b Centro de Educação Ambiental, Ciências e Matemática. Universidade Federal do Rio Grande, Rio Grande, Brasil joaosilva@furg.br

\section{Palavras-chave:}

Educação matemática.

Formação de professores.

Afetos. Percepções.

Literatura.

\section{Keywords:}

Education mathematics.

Teacher formation.

Affect. Perceptions.

Literature.
Resumo: Neste artigo, ao nos apropriarmos de um viés fenomenológico, buscamos nos traços afetivos das personagens do conto 'O Mágico de Oz' relações possíveis com a Matemática. As peculiaridades das personagens e as buscas particulares de cada uma delas deixam evidente, nesta história clássica da cultura de massa, a personificação de determinados afetos, colocando-os em uma condição de destaque a qual justifica considerar a coexistência dos mesmos no âmbito de ensinar e aprender Matemática. Percepções, medos, conceitos, crenças emergem da leitura de cada uma das personagens - Oz e suas diferentes facetas; Dorothy e a finalidade; Espantalho e o ser burro; Lenhador de Lata e os sentimentos; Leão e o medo - e se unem a uma trama de discussões teóricas que permitem pensar sobre questões vinculadas ao ensino e aprendizagem de Matemática.

Abstract: In this article, using a phenomenological approach, looking through the affective traits of the characters in The Wonderful Wizard of Oz, possible relations with Mathematics are sought. The peculiarities of each character and their particular quests make it clear, in this classic story of mass culture, the personification of certain affects, putting them in a prominent position which justifies the consideration of a coexistence in the ambit of teaching and learning Mathematics. Perceptions, fears, concepts and beliefs emerge from the reading of each of the characters $-\mathrm{Oz}$ and his different facets; Dorothy and the purpose; Scarecrow and Being Unintelligent; Tinman and the Feelings; Cowardly Lion and Fear - and unite to a plot of theoretical discussions that allow thoughts over questions regarding Mathematics. 


\section{Introdução}

Este artigo, através de um viés fenomenológico (BICUDO, 2010; BICUDO, 2011; KLÜBER; BURAK, 2008; MARTINS; BICUDO, 2006), resgata na Terra de Oz, elementos que permitem reflexões quanto às diferentes possibilidades de encontros que ocorrem com a Matemática. Encontros nos quais experienciamos crenças, percepções, sentimentos, questionamentos e vislumbramos situações que habitam nossas memórias e também os ambientes em que a Matemática é formalmente estudada (nos referimos aqui especialmente à escola). Buscamos deste modo refletir sobre os afetos enquanto um fenômeno que se mostra presente na trajetória escolar e formativa diante da Matemática. Tais reflexões emergirão neste estudo através das aproximações propiciadas pela leitura do conto 'O Mágico de Oz'.

The Wonderful Wizard of $\mathrm{Oz}$ - O Mágico de Oz - foi escrito, em 1900, pelo americano Lyman Frank Baum (1856-1919) e ilustrado por Denslow (1856-1915). A Terra de Oz foi escolhida por seu caráter mágico e suas personagens singulares, que em suas características, anseios e diálogos deixam emergir um mundo de questionamentos e analogias que aqui neste escrito entrelaçaremos com reflexões acerca da Educação Matemática. Entende-se que este sucesso e repercussão alicerça-se na expressão de sentimentos que são muito comuns à maioria das pessoas e aproximam-se de formas de relacionar-se com os afetos, as quais podem ser estendidas para outros campos, como é o caso do ensino e aprendizagem de Matemática.

O conto infantojuvenil americano foi, já em seu lançamento, um grande sucesso de vendas, sendo elaborados musicais e filmes inspirados na história. Deste modo, Oz, Dorothy, Espantalho, Lenhador de Lata e Leão acabaram sendo personagens amplamente conhecidas não apenas pelo público americano. O sucesso de $O z$ aproximou-se do de histórias como Alice in Wonderland - Alice no País das Maravilhas - do britânico Charles Lutwidge Dodgson (1832-1898), mais conhecido pelo seu pseudônimo Lewis Carroll.

Trazemos aqui a aproximação com Alice, pois em relação a esta história encontramos trabalhos como os de Sophia e Garcia (2015), que apresentaram reflexões para a Educação através de andanças pelo País das Maravilhas e pelo Bosque do Espelho. Inspirados na magia da Terra de $\mathrm{Oz}$, acompanhamos as andanças de outra garotinha, Dorothy, e em meio à magia, enxergamos Matemática, mais do que isso, enxergamos relações que estabelecemos com e diante dela. Nas linhas que seguem apresentaremos nossas reflexões.

Neste contexto, salientamos que o objetivo deste artigo é buscar nos traços afetivos das personagens de $\mathrm{Oz}$, relações com o ensino e aprendizagem de Matemática. A presença dos afetos personificados nesta história clássica da cultura de massa, coloca-os em uma condição de destaque, a qual justifica considerar a coexistência dos mesmos no âmbito de ensinar e aprender Matemática. 


\section{Primeiras aproximações - $\mathrm{O}$ mundo de $\mathrm{Oz}$}

No fantástico mundo de Oz..., Terra onde espantalho fala e quer ter miolos, lenhador de lata quer redescobrir o amor, o leão quer a coragem digna de um rei da floresta, a menina quer encontrar o caminho de volta para o conforto do lar e o grande Mágico se apresenta de acordo com quem irá receber... como nos encontramos com a Matemática? Nosso encontro será guiado em torno destas cinco personagens que brevemente indicamos no começo deste parágrafo. Mas quem sabe em Oz não estariam outras tantas possíveis reflexões?!

Poderíamos pensar nos quatro países que rodeiam a Cidade das Esmeraldas e nas bruxas que governavam as pessoas que viviam nessas regiões: Bruxas boas do Norte e do Sul e as Bruxas más do Leste e Oeste (Figura 1). Se pensarmos em Matemática e lá nos primórdios de nossos caminhos pela escolarização... falar em 'quatro' pode remeter a que? Quatro lados de um quadrado? Quatro operações básicas? Ficaremos com as últimas - as quatro operações básicas - adição, subtração, multiplicação e divisão. E o porquê dessa associação? Para somar, geralmente não encontramos problemas, multiplicação também parece sempre uma boa operação, mas começam as dívidas, retiradas, o pede emprestado daqui e de lá, divide e as vezes vira fração e surgem as complicações. Seriam essas as nossas 'Bruxas' boas e más?

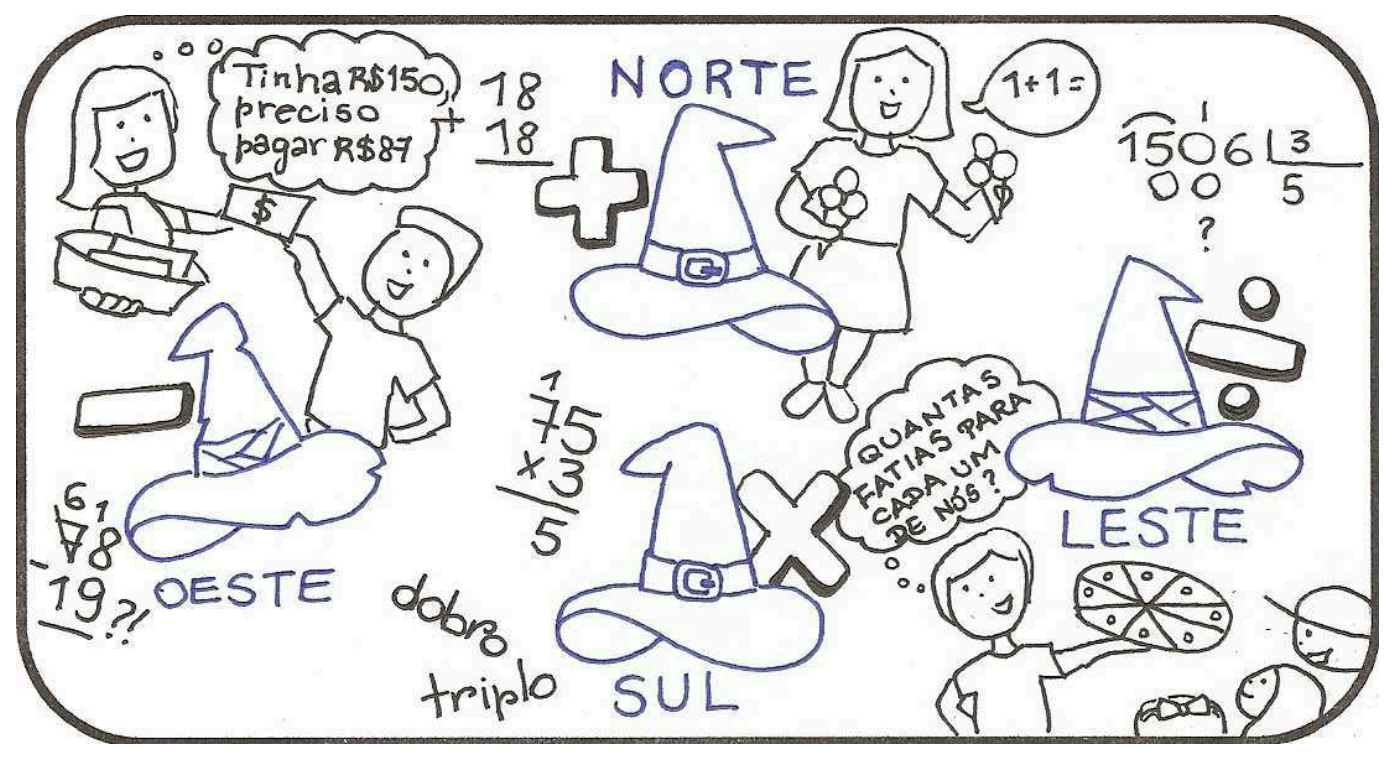

Figura 1 - O mundo de $\mathrm{Oz}$ - primeiras aproximações

Fonte: elaborada pela autora

Para pensarmos nas bruxas boas e más no que tange à Matemática podemos resgatar títulos da literatura que nos remetem tanto aos aspectos positivos quanto negativos a ela vinculados. O encanto pela Matemática pode ser encontrado nas histórias e escritos de Malba Tahan (SOUZA, 2006; TAHAN, 2001), pseudônimo de Júlio César de Mello (1895-1974), que escreveu o clássico brasileiro 'O Homem que Calculava', obra de ficção na qual resgata a Matemática sem perder o clima de aventura e romance. Monteiro Lobato (1959) também guardou um espaço para a Matemática em meio a seus tantos escritos que marcaram a 
literatura infantil brasileira e em sua obra 'Aritmética da Emília' os artistas da Matemática se apresentam às personagens do Sítio. Outra referência à magia da Matemática poderia ser o curta metragem 'Donald no País da Matemágica', produzido pela Disney em 1959 e dirigido por Hamilton Luske, no qual, em 27 minutos, o famoso pato conhece alguns conceitos e fatos históricos quanto à Matemática.

Entretanto, não resgataremos apenas os encantos, mas também a parte mais atrelada aos aspectos negativos que aparecem nos escritos. Em Monstromática (SCIESZKA, 2004) fazer contas se torna um pesadelo para a menina que acaba se tornando a heroína do livro, quando a professora diz que tudo pode ser visto como um problema de Matemática. Para Frankie Pickle (WIGHT, 2012) a Matemática é uma grande ameaça e isso se mostra ainda mais evidente diante das avaliações que precisa encarar na escola e tudo acaba aparecendo como monstros para o menino. Porém, a família toda se empenha para ajudá-lo e mostrar que na verdade a Matemática está nas coisas do dia a dia e não é tão ameaçadora assim.

Os encontros que resgataremos a seguir não requerem talvez tanta imaginação para encontrarmos a conexão metafórica que os unem... passaremos pela Terra de Oz, acompanhados de referências, tanto com bases na Educação Matemática, quanto nas questões vinculadas aos afetos que permeiam as relações no âmbito da Educação. Consideramos, sob a denominação de afetos, não só a afetividade, mas sentimentos, emoções, crenças, concepções, percepções que afetam as relações estabelecidas, principalmente, com a Matemática (GOMÉZ CHACÓN, 2003).

\section{Oz e suas facetas - percepções da Matemática}

Poderíamos ter escolhido qualquer uma das outras quatro personagens para dar continuidade a esta escrita, porém optamos pelo Grande e Terrível Oz. Extrairemos nossas reflexões, que nos levam as percepções que temos em relação à Matemática, das diversas formas como esta personagem se apresenta ao longo da história. Poucos podiam vê-lo, alguns o idolatravam, outros o julgavam totalmente inacessível... e aqueles que dele se aproximavam saíam de tal encontro com diferentes percepções. É possível estabelecer alguma semelhança com as percepções diante da Matemática?!

Resgatemos frases que saltam à cabeça quando pensamos nos comentários a ela atrelados: 'Nunca vou entender essa matéria!'; Não consigo enxergar de onde saiu esse número!';'Matemática é para os inteligentes!';'Onde na vida que vou usar polinômios?!';Tomara que não precise ver Matemática em tal curso!';'Tenho pavor de Matemática e a professora ainda era super séria e exigente!'. Muitos, também conseguem enxergar a beleza de tal disciplina, demonstram encantamento pelos números e facilidade ao lidar com os conteúdos e conceitos. Não faltam estudos que destaquem ou investiguem 
aspectos destas relações com a Matemática (ALBARELLO, 2014; KLUTH, 1997; MOURA, 2015; SILVA, 2013; THOMAZ, 1996).

Se tomarmos as aproximações com $\mathrm{Oz}$, veremos que, não só ele não era um ser que se mostrasse visível aos outros, mas também o mesmo ocorre com a Matemática. Como destaca Sadovsky (2010), frequentemente, os docentes afirmam que a Matemática está em toda parte, na tentativa de mostrar aos alunos a importância de tal estudo, porém, embora tal importância de fato exista, a Matemática não é visível em toda parte. Não só não é visível em toda parte, como se mostra de diferentes formas àqueles que se propõem ou são obrigados a estudá-la. Se relembrarmos as referências da literatura que citamos nas aproximações com as bruxas boas e más, veremos que de certo modo a Matemática acaba sim se fazendo presente em toda parte, mas é preciso que estejamos preparados para perceber esta existência.

Para Dorothy, Oz se mostrou como uma grande cabeça sem um corpo que lhe servisse de apoio, aparência que causou medo e espanto à menina. Poderíamos aproximar a grande cabeça às questões da racionalidade atrelada à Matemática, e também ao fato de que, por ser esta pura abstração e construção humana, por vezes nos perdemos no mundo das ideias. "Mesmo os conhecimentos que pareceriam mais estáveis e exatos precisam de uma relativização que os remeta às condições de produção da qual se cercaram, ou à sua configuração" (CORTELLA, 2006, p. 103).

Para o Espantalho, surgiu uma linda mulher com duas asas suaves que nele despertou uma expressão de doçura. Aqui, poderíamos remeter às relações com o afeto estabelecido nas relações professor-aluno e a forma como em algumas situações tais percepções e motivações extrapolam aquelas relacionadas à disciplina em si. Podemos nos voltar à formação de professores e pensar nas marcas por eles deixadas e o impacto causado por suas práticas.

As pesquisas têm mostrado que os professores afirmam que sua prática cotidiana tem mais importância no seu modo de ser do que a formação acadêmica que por ventura tiveram. E ainda, que o seu comportamento docente é inspirado em professores que marcaram a sua própria trajetória educacional. Estes dados reforçam a necessidade de tratar os processos pedagógicos de forma contextualizada. Mostram que a relação professor-aluno é fundamental, capaz de deixar marcas no indivíduo por grande parte da existência. É preciso resgatá-la, compreendê-la e redimensiona-la (CUNHA, 1991, p. 155).

O Lenhador de Lata deparou-se com um Monstro horrível, cabeça como a de um rinoceronte, com cinco olhos, cinco braços compridos, cinco pernas finas e compridas e todo coberto de pelos, uma decepção para aquele que esperava a linda mulher. Aqui caberia novamente relembrar das referências a monstros em histórias como a Monstromática e a de Frankie Pickle na qual o menino enxerga monstros onde na verdade são números e exercícios a serem enfrentados. Mais a frente resgataremos estudos mais teóricos acerca da temática. Já o Leão enfrentou uma assustadora e brilhante bola de fogo para a qual mal conseguia olhar (BAUM, 2013). 
A cada aproximação, um relato e a cada novo contato, uma decepção ou surpresa. Se para uns despertou medo e espanto, para outros doçura e encanto. $\mathrm{O}$ mesmo acontece com aqueles que se aproximam da Matemática. Para uns, tudo é tão assustador e complexo, para outros, parece tudo tão claro e compreensível... por vezes parece difícil compreender que se possa ter uma percepção tão diferente de uma mesma coisa. Se pensarmos nas explicações acerca de exercícios ou situações-problemas que envolvam Matemática: 'Mas como não consegue entender?!' 'Era só fazer tal coisa'. E o que para uns parece tão óbvio, para outros ganha inúmeros braços e pernas e torna-se um grande monstro (Figura 2).

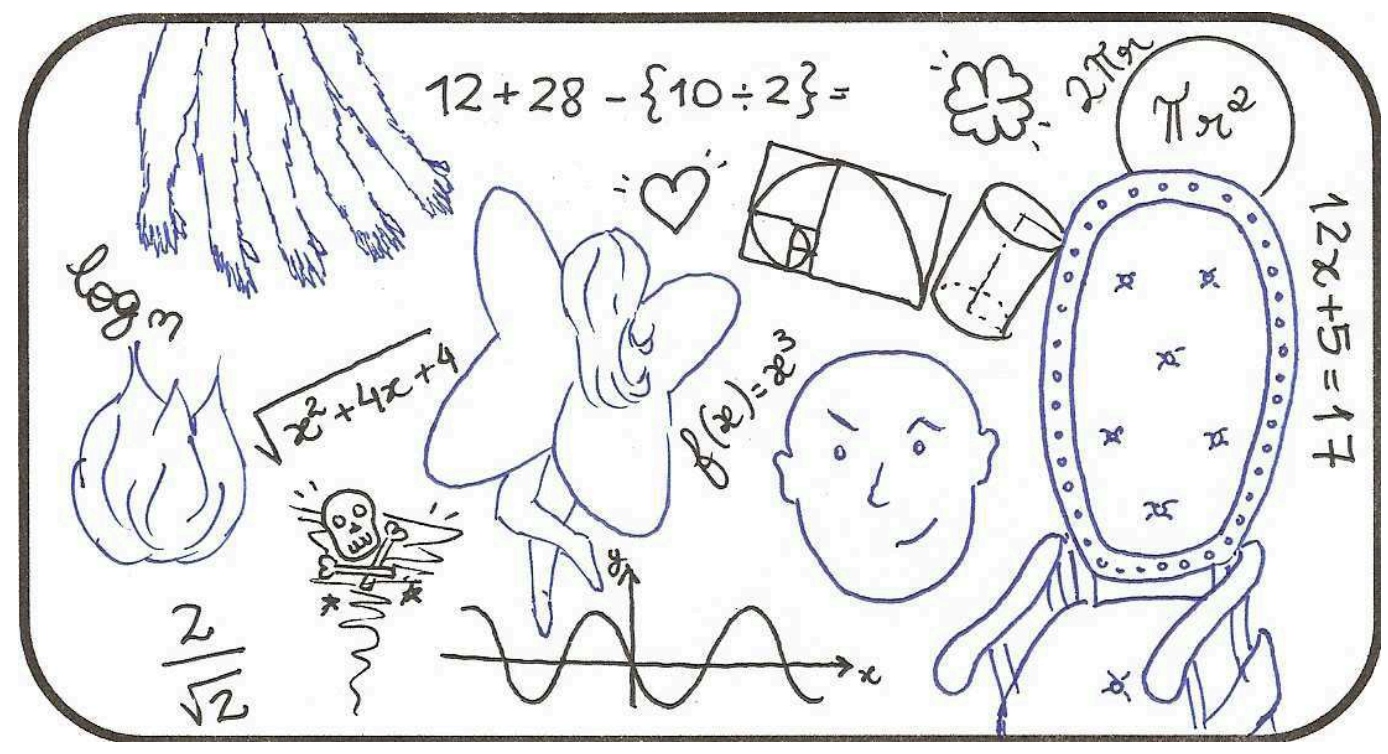

Figura 2 - Oz e suas facetas

Fonte: elaborada pela autora

\section{Dorothy e o caminho para casa -final certo ou finalidade}

A história do livro se passa com a menina Dorothy tentando encontrar o caminho que a leve de volta para onde morava com seus tios, já que com a passagem de um ciclone a casa onde estava foi arrancada e ela e seu cachorro foram parar na estranha Terra de Oz. Tudo que se passa ao longo da história pouco significa para a menina, além do fato de poder estar mais perto de conseguir voltar para casa com seus tios. Não importa o caminho que precise seguir, mas sim a busca incessante pelo resultado final. E aqui podemos tomar duas perspectivas que se apresentam quando trabalhamos com a Matemática (Figura 3): quando mecanicamente se busca o resultado correto, ou quando recorrentemente somos questionados, enquanto professores, sobre a utilidade daquilo que estamos ensinando (LORENZATO, 2006; MACHADO, 2012). 


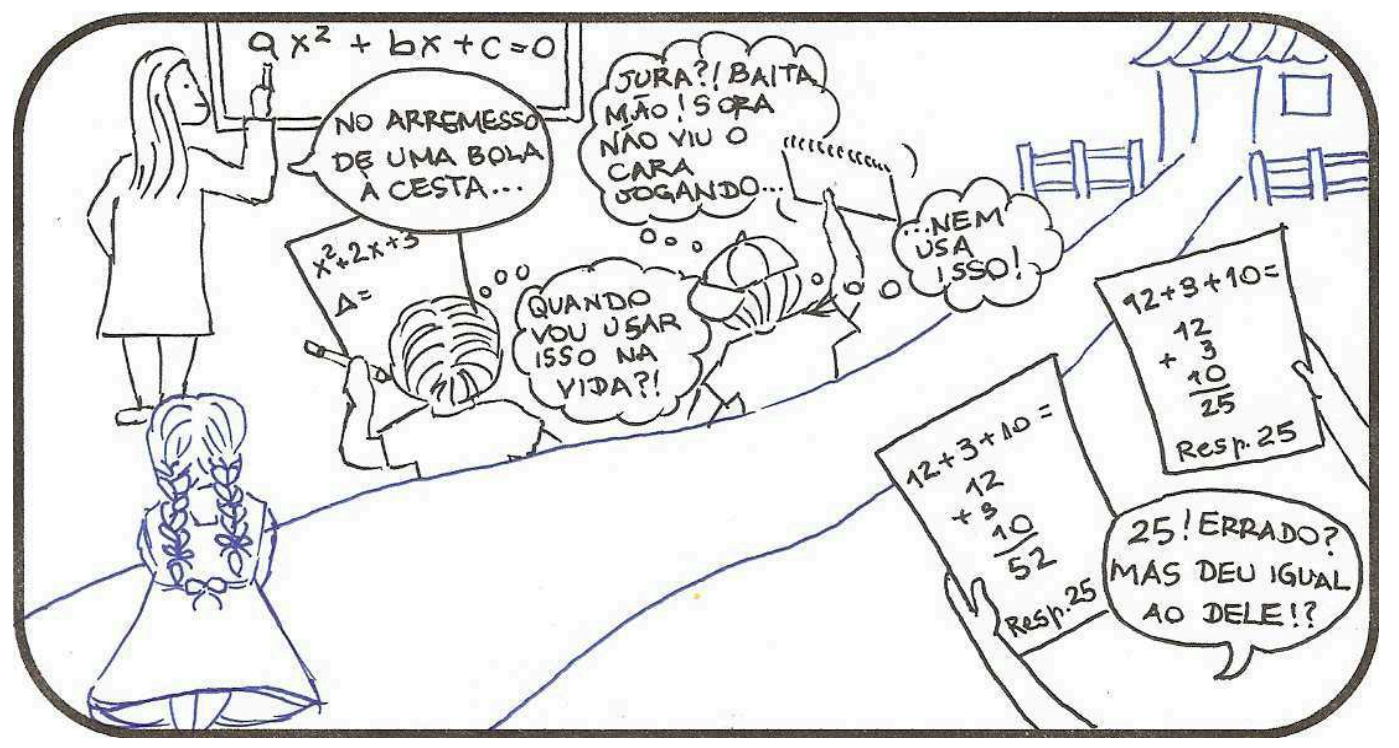

Figura 3 - Dorothy e o caminho para casa

Fonte: elaborada pela autora

Por vezes, nas resoluções de problemas ou nas atividades matemáticas em geral, o foco é para a obtenção de determinado resultado correto. E de certo modo é isso que comumente é avaliado na escola, não propriamente as compreensões e entendimentos aos quais os alunos chegam e sim os resultados esperados. Não raro, a Matemática está atrelada à memorização de fórmulas e procedimentos e, não necessariamente a uma compreensão ou atribuição de sentidos. Embora quanto ao sentido possamos nos remeter à Panizza (2006, p. 19):

A palavra "sentido" parece estar cada vez mais presente nas preocupações dos professores sobre o ensino da matemática. "Como conseguir que os alunos encontrem o sentido da atividade matemática?", "Os alunos agem mecanicamente sem dar sentido ao que fazem", entre outras, são expressões habituais dos professores. A palavra "sentido" parece explicar intenções, conquistas e frustrações. No entanto, questões como qual significado se atribui à palavra, onde se encontra 0 sentido, se é algo que o docente dá ou o aluno constrói e em que condições, longe de serem claras e compartilhadas, comportam profundas diferenças e contradições.

Aproximando-nos da questão da utilidade da Matemática estudada, podemos facilmente recordar de situações em que os estudantes se utilizam de expressões como: 'Mas quando na vida vou usar isso?'; 'Para que serve tal conhecimento?'; 'Não tem fundamento algum estudar um monte de coisas que nunca iremos utilizar!'. Toledo e Toledo (2009) destacam como sendo uma pergunta comum entre os estudantes o: 'Para que eu preciso aprender isso?'. Os pesquisadores afirmam que “embora um dos objetivos explícitos do ensino da matemática seja preparar o estudante para lidar com atividades práticas que envolvam aspectos quantitativos da realidade, isso acaba não ocorrendo" (TOLEDO; TOLEDO, 2009, p. 7). Para pensarmos a respeito desses aspectos agregamos as reflexões de Machado (2012, p. 13): 
É certo que as ferramentas matemáticas nos ajudam a lidar com a realidade concreta. Seu uso reiterado no dia a dia e sua importância como linguagem das Ciências, em todas as áreas, são indiscutíveis. Mas há algo na Matemática que escapa a qualquer sentido prático/utilitário, que expressa relações, às vezes surpreendentes, e nos ajuda a construir o significado do mundo da experiência, no mesmo sentido em que um poema o faz. Um poema nunca se deixa traduzir em termos de utilidade prática: ele nos faz sentir, compreender, instaura novos sentidos, dá vida a contextos ficcionais. [...] A Matemática partilha com a poesia esse potencial para criar novos mundos, inspirados na realidade, mas cheios de encantamento. Para enfrentar as dificuldades com o ensino de Matemática, mais do que despertar o interesse pelas suas aplicações práticas, é fundamental desvelar sua beleza intrínseca, sua vocação para a apreensão dos padrões e das regularidades na natureza, suas relações diretas com os ritmos, com a música, com as artes de modo. [...] É necessário pensar e sentir, consumir e produzir, compreender e fruir os temas que estudamos.

Dessa forma, precisamos resgatar o encanto perdido em relação à Matemática. Ainda que por vezes, prevaleça a busca pela utilidade - aplicabilidade prática - e finalidade, não reside única e exclusivamente na ausência da clareza desses fatores o desencanto pela Matemática. Machado (2012) além das relações que faz com os poemas, também fala sobre os contos de fadas, diante dos quais as crianças mostram encantamento sem que muitas vezes haja uma conexão com a realidade. $O$ autor destaca, que não começamos um conto apresentando diretamente a moral da história e é muitas vezes assim que queremos trabalhar com a Matemática, apresentamos fórmulas, modos de fazer e atropelamos as possibilidades de explorações acerca do tema abordado.

\section{Espantalho e o ser burro - a capacidade intelectual}

- Ora, mas você não sabe? - devolveu ela, espantada.

- A verdade é que não; não sei de nada. É que eu sou recheado de palha, e por isso não tenho cérebro - respondeu ele, em tom triste.

[...] - O fato é que não me incomodo de ter as pernas, o corpo e os braços recheados de palha [...] Mas não quero que as pessoas digam que eu sou burro, e se a minha cabeça continuar recheada de palha em vez de miolos, como a sua, como é que eu vou conseguir aprender alguma coisa? (BAUM, 2013, p. 39)

$* * *$

“(...) tenho certeza de que o grande $\mathrm{Oz}$ vai me dar um cérebro assim que nós chegarmos à Cidade das Esmeraldas."

E Dorothy respondeu, com toda a sinceridade:

- Espero que sim, já que você quer tanto.

- Quero sim - respondeu o Espantalho. - É muito ruim essa sensação de saber que você é burro. (BAUM, 2013, p. 46)

- Se a estrada entra na floresta, em algum lugar ela precisa sair - disse o Espantalho. - E como a Cidade das Esmeraldas fica na outra ponta da estrada, temos de seguir por ela.

- Isso qualquer um sabe - disse Dorothy.

- Sem dúvida, e é por isso que eu sei - respondeu o Espantalho. - Se precisasse de um cérebro para descobrir, eu não teria dito nada (BAUM, 2013, p. 47).

Começamos pelo resgate de pequenos diálogos entre Dorothy e o Espantalho, nos quais podemos evidenciar situações em que a inteligência, ou poderíamos dizer a capacidade cognitiva, é questionada ou posta à prova. Como se houvesse uma resposta muito óbvia: 'Ora, 
mas você não sabe?' Diante de tal questionamento o Espantalho admite que não sabe e que gostaria muito de ter miolos para que os outros não dissessem que ele é burro.

Mais adiante na história, o próprio Espantalho afirma ser muito ruim a sensação de saber que é burro. Se, anteriormente, o desagradável era que os outros lhe dissessem isso, com o tempo ele mesmo já se convence de sua burrice, desejando profundamente ter miolos. Não é preciso avançar muito na história para nos depararmos com mais uma situação... O Espantalho realiza algumas constatações diante das quais Dorothy afirma: 'Isso qualquer um sabe!' Frente a esta afirmação, o coitado do Espantalho admite que sem dúvida alguma, ele só sabe porque qualquer um saberia e caso contrário, se precisasse ter cérebro para chegar a tal conclusão, ele nem teria dito nada.

Percebemos que às vezes pequenas frases ditas 'espontaneamente' podem causar impactos como os citados, seja por pressupor uma obviedade que não existe de maneira unânime, ou por subestimar algumas conclusões e colocações realizadas. Tanto em uma perspectiva, quanto em outra, podemos notar tristeza ou inibição por parte de quem se sente em desvantagem ou talvez diminuído. No último trecho, destacamos ainda o momento em que o Espantalho fala que não teria dito nada... e aqui é percebido o fato de que a sensação de incapacidade vai nos levando a nos eximirmos da chance de arriscar ou de expor nossos pensamentos.

Lorenzato (2006), tomando como suporte experiências de magistério e pesquisas educacionais, apresentou em 'Para aprender Matemática' alguns princípios a serem seguidos antes, durante e depois das aulas. Dentre os 25 princípios apresentados temos um que se refere a tomar cuidado com o simples, o óbvio e o acerto. E pensemos aqui não mais em simples e óbvio no sentido apenas da fala, mas também na forma como, enquanto professores, percebemos e nos colocamos diante daquilo que o aluno nos apresenta.

O simples, o evidente e o acerto têm sido interpretados, por muitas pessoas, como facilitadores ou indicadores de aprendizagem. No entanto, eles não devem ser subestimados pelo professor, uma vez que podem, também, se tornar complicadores para a significativa aprendizagem. Isto porque o acerto dos alunos nem sempre é resultado de compreensão, e porque o simples e o evidente podem ser considerados pelo professor como merecedores de pouca ou nenhuma explicação aos alunos (LORENZATO, 2006, p. 39).

Quando em processo de formação ou diante da necessidade de elaborar alguma aula sobre determinado conteúdo, por muitas vezes, mesmo aqueles que nunca tiveram dificuldades e restrições quanto à Matemática, se deparam com dúvidas e receios. Talvez a seguinte situação justamente se apresente pelo fato de o simples, o evidente e os acertos nem sempre serem indicadores de uma significativa aprendizagem ou até mesmo compreensão. E aqui se entrelaçam as colocações feitas anteriormente, quando falamos de Dorothy e na relação com a Matemática, comentamos acerca da busca pela resposta final correta. Em 
algumas situações é preciso levar em conta, enquanto professores, que "o acerto pode camuflar o erro e, também, aquilo que é simples ou evidente, para nós, geralmente não o é para os alunos" (LORENZATO, 2006, p. 42).

Ao se autodenominar como burro, o Espantalho nos leva a refletir sobre o autoconceito que vamos construindo acerca de nossas capacidades e sobre como a questão da inteligência pode ser percebida no âmbito da Matemática (Figura 4). Carvalho (1991), ao dar destaque à concepção que geralmente norteia o ensino da Matemática, evidencia algumas características como ser esta uma área de conhecimento pronta, acabada, perfeita, pertencente apenas ao mundo das ideias e servindo, em alguns aspectos, de modelo a outras ciências. Segundo a pesquisadora, uma das consequências desta visão de Matemática é a vinculação ao sucesso na disciplina, sendo este um balizador da inteligência "na medida em que uma ciência tão nobre e perfeita só pode ser acessível a mentes privilegiadas, os conteúdos matemáticos são abstratos e nem todos têm condições de possuí-los" (CARVALHO, 1991, p. 15). Segundo Albarello (2014, p. 14) "parece ser senso comum que a Matemática é para indivíduos dotados de habilidades diferenciadas. E essa postura talvez venha de épocas em que essa área de conhecimento era privilégio de alguns".

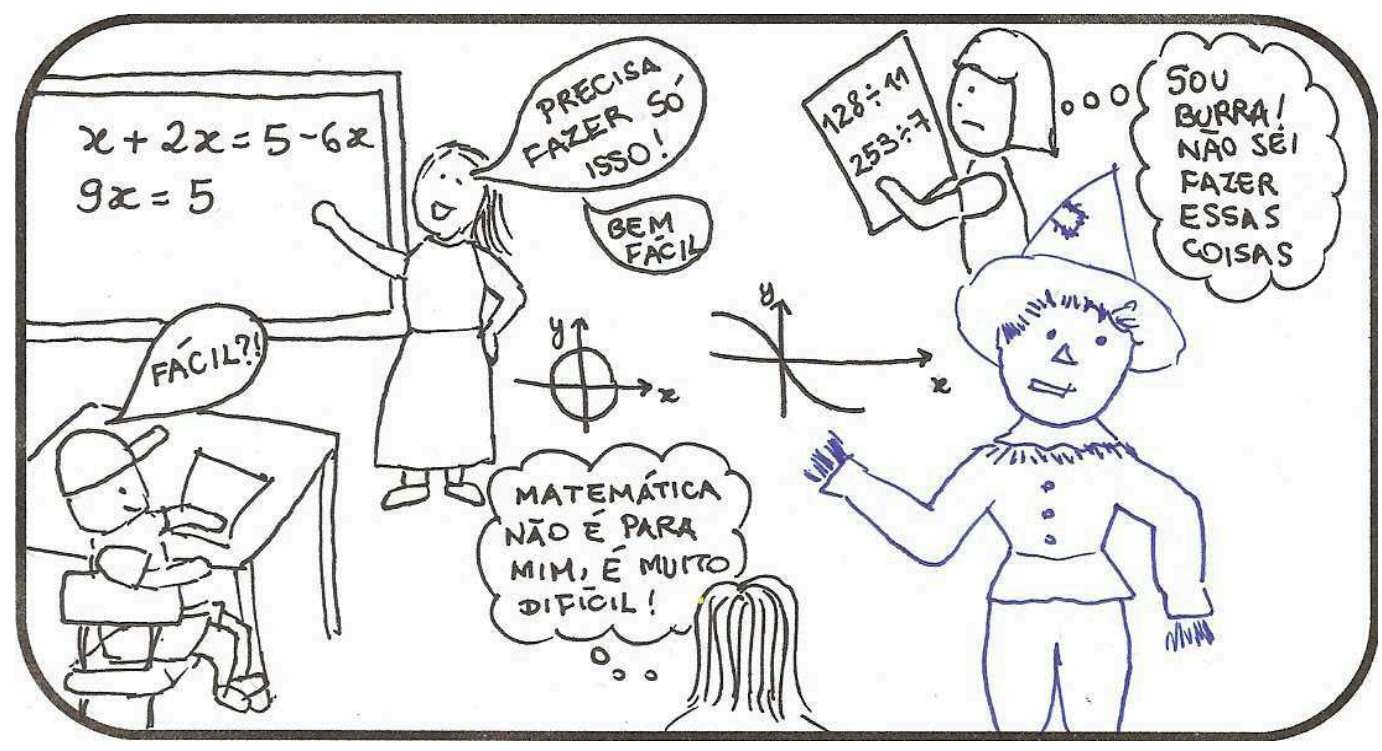

Figura 4 - Espantalho e o ser burro Fonte: elaborada pela autora

Falar na questão da inteligência em relação à Matemática parece estar nos remetendo apenas ao contexto escolar, mas não, pensemos também no contexto da formação de professores. É necessário que estes percebam os conhecimentos matemáticos que possuem e possam apropriar-se gradativamente daqueles que não foram plenamente compreendidos ao longo da história de vida escolar. "Se o professor, durante a sua formação, não vivenciar a experiência de sentir-se capaz de entender Matemática e de construir algum conhecimento matemático, dificilmente aceitará tal capacidade em seus alunos" (CARVALHO, 1991, p. 17). 


\title{
Lenhador de Lata sem coração- os afetos
}

O afeto é assim. No mundo atual, parece uma novidade, mas ele existe desde que respiramos. Decerto, é uma respiração; transpiração e inspiração para a vida (CUNHA, 2008, p. 20).

Pensar no Lenhador de Lata é lembrar da busca pelo coração e pela capacidade de voltar a ter sentimentos. Falar em sentimentos no âmbito da Matemática remete ao desgosto manifesto em tantas pesquisas, ou talvez, possamos dizer que o não gostar de matemática tenha sido concebido em um 'senso comum' ao menos quando pensamos em professores que ensinam matemática para crianças.

Estudos como o de Thomaz (1996) - Não gostar de Matemática que fenômeno é este? - mostram que pensar sobre esta temática é ao menos pertinente. Aqueles que lidam com professores em formação, principalmente no âmbito da Pedagogia e/ou Magistério, destacam em seus estudos a presença de acadêmicos que esboçam, se não um desgosto pela disciplina, ao menos um alívio por estarem em cursos onde supostamente não terão de encarar muito a Matemática.

Carvalho (1991) considera crucial a questão do desgosto por Matemática manifestado por alunos que procuram o curso de Habilitação ao Magistério. A pesquisadora refere-se a este dado como sendo uma maioria absoluta de alunos que manifeste este desgosto, mas optamos aqui por não quantificar e sim apenas considerar a existência de tal postura. Quanto à manifestação deste desgosto a pesquisadora destaca que seria difícil supor o contrário.

\begin{abstract}
Num ensino onde é necessário submeter-se à autoridade da Matemática, é impossível entender, pois "compreender Matemática" torna-se privilégio das cabeças mais bem-dotadas; acaba-se por negar todas as vivências anteriores relativas à quantificação, já que não se "enquadram" na perfeição da Matemática; quem poderia gostar de uma "disciplina" como essa? A consequência mais desastrosa de tal fato talvez seja a total passividade com que os alunos se colocam perante qualquer aula, esperando que o professor lhes "explique" o que devem "compreender" e lhes diga "como" fazer. Se não é o professor, é o livro a suprema "autoridade" que saberá o melhor caminho para resolver o problema básico: "ser promovido em Matemática". Aprender parece-lhe um objetivo distante e inatingível, só lhe resta escolher uma carreira que não requisite conhecimentos matemáticos (CARVALHO, 1991, p. 17).
\end{abstract}

Mostram-se nas crenças e concepções sobre a Matemática alguns aspectos fortemente arraigados. Ao pensarmos nos afetos em Matemática nos remetemos a Gómez Chacón (2003) que destaca o aspecto cíclico da relação que se estabelece entre afetos - emoções, atitudes e crenças - e aprendizagem. A pesquisadora afirma que se

por um lado, a experiência do estudante ao aprender matemática provoca diferentes reações e influi na formação de suas crenças. Por outro, as crenças defendidas pelo sujeito têm uma consequência direta em seu comportamento em situações de aprendizagem e em sua capacidade de aprender (GÓMEZ CHACÓN, 2003, p. 23).

Devemos pensar nesses afetos também no sentido do autoconceito que o estudante constrói de si enquanto aprendiz de Matemática, ao receber contínuas mensagens do que signifique conhecer Matemática e sobre o significado social do que está aprendendo (Figura 
5). Para Gómez Chacón (2003) o autoconceito está relacionado com as atitudes, a visão do mundo matemático e a identidade social do estudante, sendo assim, tem grande influência na visão que este estudante concebe de Matemática e sua reação para com ela.

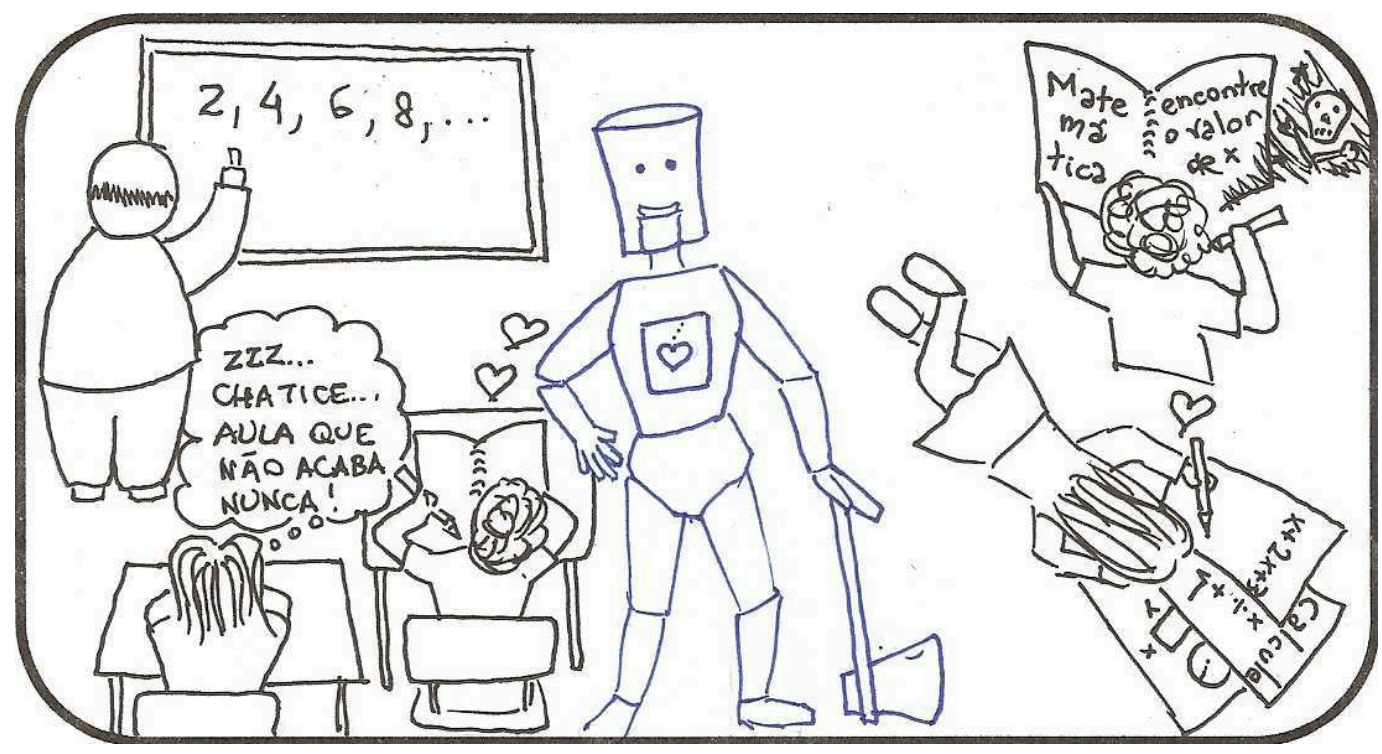

Figura 5 - Lenhador de Lata e os afetos

Fonte: elaborada pela autora

\title{
Leão covarde - o medo ou fobia
}

Chegamos a nossa última personagem, o Leão que buscava encontrar a coragem. Nos remetermos à coragem em termos de Matemática faz pensar nos medos e fobias em torno da disciplina ou até mesmo em relação aos professores que marcaram algumas trajetórias. Aqui podemos destacar estudos como o de Albarello (2014) e Felicetti (2007). O primeiro debruça um olhar sobre a Matemática e questiona se há fobia ou encantamento, enquanto o segundo indica o sentimento de matofobia como um fator que intervém negativamente no processo de ensino e aprendizagem da disciplina.

\begin{abstract}
Sabendo que o aprendizado matemático inicia desde muito cedo, a fobia pela disciplina também é trazida por alguns desde muito cedo. A matemática entra na vida dos alunos no início de suas atividades escolares. Toda a estrutura de um aprendizado com sucesso é construída desde a pré-escola, com as pequenas noções aritméticas. $\mathrm{O}$ primeiro contato com a matemática formal é muito significativo para o despertar do gosto pela mesma. Práticas interessantes e bem elaboradas fazem desse momento uma situação de satisfação e entusiasmo e que marca e constrói na vida do educando uma afinidade com a disciplina (ALBARELLO, 2014, p. 44).
\end{abstract}

Nos voltemos então à matofobia, termo que não foi cunhado por Felicetti, mas a pesquisadora foi a responsável por nos guiar ao texto de Papert (1980). Seymour Papert (1928 - 2016) foi um matemático que, inspirado em suas leituras de Piaget e compreensões sobre os métodos de Montessori, buscou trabalhar a informática com crianças, de modo que a aprendizagem pudesse ser considerada não apenas em um aspecto cognitivo, mas também 
emocional. Papert foi o criador da linguagem de programação LOGO ${ }^{1}$, em 1967, e é exatamente no livro 'LOGO: Computadores e Educação' que o matemático apresenta um capítulo intitulado 'Matofobia: o medo de aprender'.

Aos meus ouvidos, a palavra matofobia leva a duas associações. Uma delas é o conhecido medo da matemática, que muitas vezes tem a intensidade de uma verdadeira fobia. A outra vem do significado do radical mathe. Em grego significa "aprender" de maneira geral.

Em nossa cultura, o medo de aprender não é menos endêmico (embora mais freqüentemente dissimulado) do que o medo da matemática. As crianças iniciam sua vida como aprendizes ávidas e competentes. Aprendem a ter problemas com a aprendizagem em geral e com a matemática em particular. Em ambos os sentidos de "mathe" há uma mudança de "matófilo" para "matófobo", de amante da matemática e da aprendizagem para uma pessoa fóbica em ambas (PAPERT, 1980, p. 60).

Felicetti (2007) se apropria do termo matofobia considerando-o como um sentimento negativo a respeito da Matemática. Tal sentimento é identificado inicialmente na escola onde a Matemática acaba se tornando o vilão na vida escolar de muitos alunos (Figura 6). A pesquisadora coloca o sentimento de matofobia como um fator que pode vir a contribuir para o fracasso escolar de modo que não só prejudique a aprendizagem da Matemática, mas que possa também interferir no desenvolvimento de outros conteúdos curriculares.

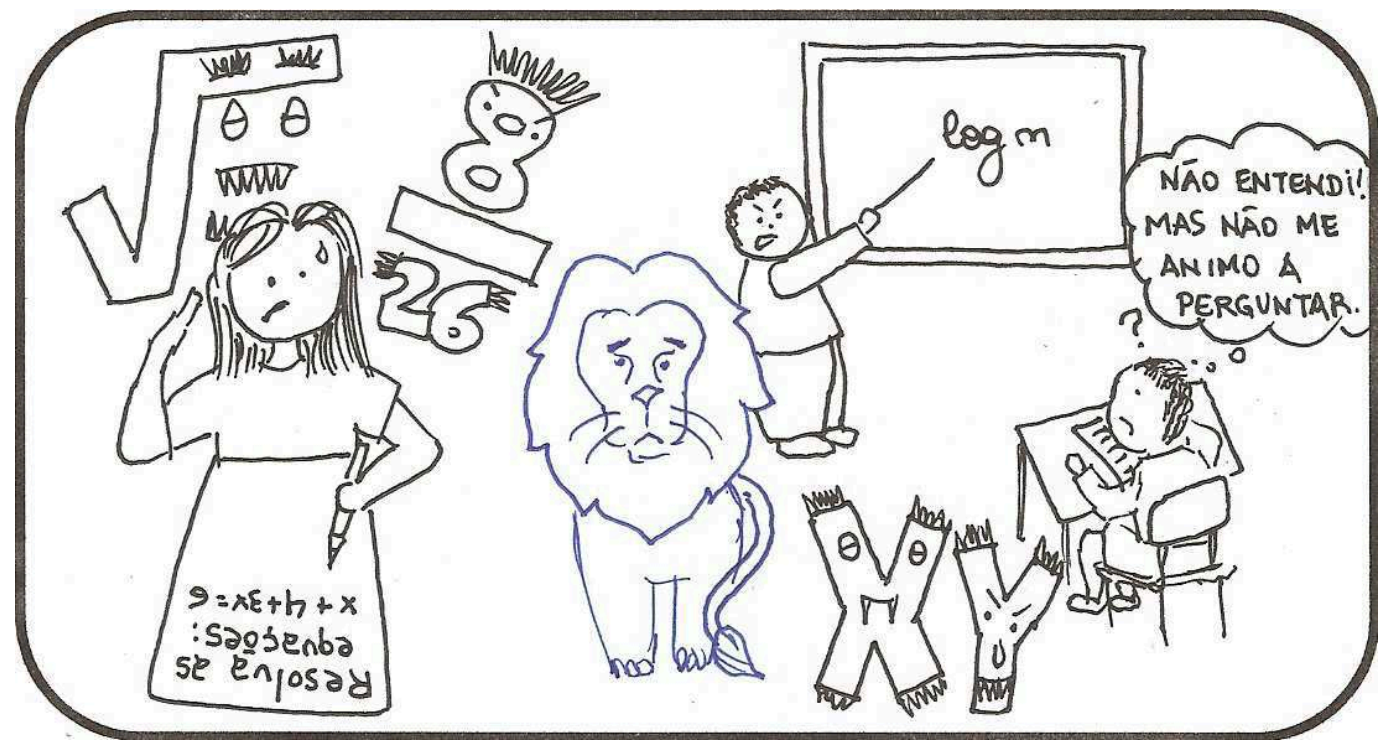

Figura 6 - Leão e o medo

Fonte: elaborada pela autora

\section{Considerações finais}

Encontrar em 'O Mágico de Oz' traços de afetos personificados em cada uma das personagens, que possibilitam a emergência de relações com a Matemática, permite que voltemos o olhar para situações que permeiam seu ensino e aprendizagem. Em uma pesquisa

\footnotetext{
${ }^{1}$ LOGO, ou a famosa tartaruguinha, fez parte, para a geração que viveu a disseminação dos primeiros microcomputadores no Brasil, do primeiro contato com computadores nas aulas de informática nas escolas. As aulas básicas de programação permitiam que coordenadas fossem programadas e a tartaruga se deslocasse no espaço bidimensional de modo a favorecer o aprendizado de conceitos matemáticos vinculados a construções geométricas e plano cartesiano, mesmo que intuitivamente.
} 
de cunho fenomenológico buscamos, com o resgate de referenciais que contribuem para reflexões acerca da Educação Matemática, explorar as diferentes categorias de afetos que emergem da leitura das personagens.

Desse modo, percebemos afetos que se mostram tanto nas relações com a disciplina em si, nas relações interpessoais, principalmente entre professores e alunos, quanto nas relações intrapessoais e autoconceitos que vão sendo construídos quanto às capacidades pessoais para a compreensão e trabalho com a Matemática. Dar ênfase a essas relações permite que possamos estar mais atentos a perceber a forma como afetamos e somos afetados em relação à Matemática.

Por conseguinte, podemos voltar o olhar também à formação de professores que ensinam Matemática, na forma como esses afetos se fazem presentes em suas trajetórias e de que modo podem ser ressignificados nas práticas enquanto professores. Quais facetas da Matemática estão sendo percebidas e priorizadas nas formações e práticas? Quais sentimentos estão arraigados a nossas memórias do tempo de escolarização? Qual grau de confiança presente na relação com a Matemática? Quais percepções e crenças nos constituem no âmbito da Matemática? Optamos por incluir questionamentos, ainda que seja aqui o fechamento desta escrita, pois é com intenção de que tais retomadas possam ser feitas que conduzimos tais aproximações. Aqui podemos nos aproximar novamente das personagens - Oz, Dorothy, Espantalho, Lenhador de Lata e Leão - e na busca por perceber os traços de afeto que exaltam, direcionar uma reflexão acerca do que vem sendo construído no contexto do ensinar e aprender Matemática.

\section{Referências}

ALBARELLO, Q. R. S. Um olhar sobre a Matemática: fobia ou encantamento? Dissertação (Mestrado em Educação) - Universidade Regional Integrada do Alto Uruguai e das Missões, Frederico Westphalen, 2014.

BAUM, L. F. O mágico de Oz. Tradução de Sergio Flaskman. Rio de Janeiro: Zahar, 2013.

BICUDO, M. A. V. (Org.). Filosofia da educação matemática:fenomenologia, concepções, possibilidades didático-pedagógicas. São Paulo: Editora UNESP, 2010.

BICUDO, M. A. V. (Org.). Pesquisa qualitativa segundo a visão fenomenológica. São Paulo: Cortez, 2011.

CARVALHO, D. L. Metodologia do Ensino de Matemática. São Paulo: Cortez, 1991.

CORTELLA, M. S. A escola e o conhecimento: fundamentos epistemológicos e políticos. 10. ed. São Paulo: Instituto Paulo Freire, 2006.

CUNHA, A. E. Afeto e aprendizagem: amorosidade e saber na prática pedagógica. Rio de Janeiro: Walk Ed., 2008. 
CUNHA, M. I. A relação professor-aluno. In: VEIGA, I. P. A. (Org.). Repensando a didática. Campinas: Papirus, 1991. p. 145-158.

FELICETTI, V. L. Um estudo sobre o problema da MATOFOBIA como agente influenciador nos altos índices de reprovação na $1^{a}$ série do Ensino Médio. Dissertação (Mestrado em Educação em Ciências e Matemática) - Pontifícia Universidade Católica do Rio Grande do Sul, Porto Alegre, 2007.

GÓMEZ CHACÓN, I. M. Matemática Emocional: os afetos na aprendizagem matemática. Tradução de Daisy Vaz de Moraes. Porto Alegre: Artmed, 2003.

KLÜBER, T. E.; BURAK, D. A fenomenologia e suas contribuições para a Educação Matemática. Práxis Educativa, v. 3, n. 1, p. 95-99, 2008.

KLUTH, V. S. O que acontece no encontro Sujeito-Matemática? Dissertação (Mestrado em Educação Matemática) - Universidade Estadual Paulista, Rio Claro, 1997.

LOBATO, M. Aritmética da Emília. São Paulo: Editora Brasiliense, 1959.

LORENZATO, S. Para aprender matemática. Campinas: Autores Associados, 2006. (Coleção Formação de professores)

MACHADO, N. J. Matemática e educação: alegorias, tecnologias, jogo, poesia. 6. ed. São Paulo: Cortez, 2012. (Coleção questões da nossa época; v. 43)

MARTINS, J.; BICUDO, M. A. V. Estudos sobre existencialismo, fenomenologia e educação. 2. ed. São Paulo: Centauro, 2006.

MOURA, J. F. Narrativas de vida de professores da educação infantil na constituição da formação docente: as marcas e as ausências da matemática escolar. Dissertação (Mestrado em Educação). Universidade São Francisco, Itatiba, 2015.

PANIZZA, M. Ensinar matemática na educação infantil e nas séries iniciais: análise e propostas. Tradução de Antonio Feltrin. Porto Alegre: Artmed, 2006.

PAPERT, S. Logo: Computadores e Educação. Tradução de José Armando Valente e Colaboradores. São Paulo: Brasiliense S. A., 1980.

SADOVSKY, P. O ensino de matemática hoje: enfoques, sentidos e desafios. Tradução de Antonio de Padua Danesi. 1. ed. São Paulo: Ática, 2010.

SCIESZKA, J. Monstromática. Tradução de Iole de Freitas Druck. São Paulo: Companhia das Letrinhas, 2004.

SILVA, T. L. C. Futuros professores de Matemática: concepções, memórias e escolhas profissional. Dissertação (Mestrado em Educação) - Universidade Federal do Espírito Santo, Vitória, 2013.

SOPHIA, G. S.; GARCIA, P. B. Andanças pelo País das Maravilhas e pelo Bosque do Espelho: Reflexões de Alice para a Educação. Jundiaí, Paco Editorial: 2015.

SOUZA, J. C. M. Matemática divertida e curiosa. 24. ed. Rio de Janeiro: Record, 2006.

TAHAN, M. O homem que calculava. 55. ed. Rio de Janeiro: Record, 2001. 
THOMAZ, T. C. F. Não Gostar de Matemática que fenômeno é este? Dissertação (Mestrado em Educação) - Pontifícia Universidade Católica do Rio Grande do Sul (PUCRS), Porto Alegre, 1996.

TOLEDO, M. B. A.; TOLEDO, M. A. Teoria e prática de Matemática: como dois e dois. São Paulo: FTD, 2009.

WIGHT, E. Frankie Pickle e a Ameaça Matemática. Tradução de Marina Dalcorsso Fodra. São Paulo: Fundamento, 2012.

\section{SOBRE OS AUTORES}

LETÍCIA DE QUEIROZ MAFFEI. Pedagoga e Professora de Matemática. Mestre em Ensino de Ciências e Matemática pela Universidade Federal de Pelotas. Doutora em Educação em Ciências pela Universidade Federal do Rio Grande - FURG. Atuou como professora de Matemática da rede pública de ensino e atualmente é pedagoga no Hospital Universitário Dr. Miguel Riet Corrêa Jr - Hospital Universitário da FURG.

JOÃO ALBERTO DA SILVA. Pedagogo e Psicólogo. Pós-Doutor em Educação Matemática pela Universidade Federal de Pernambuco e Doutor em Educação pela Universidade Federal do Rio Grande do Sul - UFRGS. Professor da Universidade Federal do Rio Grande - FURG no Centro de Educação Ambiental, Ciências e Matemática CEAMECIM e no Programa de Pós-Graduação em Educação em Ciências - PPGEC. 